\title{
ARBITRAGEM NOS CONTRATOS INTERNACIONAIS DE COMÉRCIO ENTRE BRIC: A HARMONIZAÇÃO COMO INSTRUMENTO PARA DINAMIZAÇÃO DO COMÉRCIO
}

\section{ARBITRATION AGREEMENTS IN INTERNATIONAL TRADE IN THE BRIC COUNTRIES: HARMONIZATION AS INSTRUMENT TO IMPROVE TRADE

\author{
${ }^{1}$ Arlindo Eduardo de Lima Júnior \\ ${ }^{2}$ Eugênia Cristina Nilsen Ribeiro Barza
}

\section{RESUMO}

Este trabalho analisará a Arbitragem nos países do BRIC a fim de verificar as regras em vigor nestes e observar se seriam apropriadas à dinamização do comércio. Com a aproximação, as relações comerciais entre o Brasil, Rússia, Índia, China e aumentou. Assim, também espera-se o aumento de litígios entre as empresas. Prever como serão resolvidas as questões contratuais por meio de arbitragem aumenta a segurança em relação às expectativas contratuais e, por consequência, levaria dinamização ao comércio internacional de tecnologias.

Palavras-chave: Bric, Contratos internacionais, Arbitragem internacional, Sentença arbitral

\begin{abstract}
This paper analyses the arbitration in the BRIC countries in order to verify if the rules in these countries are proper to advancing trade. With the approach the trade relations among Brazil, Russia, India and China increased. Therefore, it is also expected increase in the disputes between companies. Knowing how to will be resolved contractual issues through arbitration, increase safety about contractual expectations and improve the international trade.
\end{abstract}

Keywords: Bric, International contracts, International arbitration, Arbitral award

\footnotetext{
${ }^{1}$ Doutorando em Direito pela Universidade Federal de Pernambuco - UFPE, Pernambuco, PE. (Brasil). E-mail: edu.dir.est@ hotmail.com

${ }^{2}$ Doutora em Direito e Professora na Universidade Federal de Pernambuco - UFPE, Recife, Pernambuco, PE. (Brasil). E-mail: ecnrbarza@terra.com.br
} 


\section{INTRODUÇÃO}

As controvérsias envolvendo particulares, em uma determinada ordem jurídica soberana, suscita uma série de questionamentos sobre métodos para sua pacificação.

Poder-se-ia tratar da arbitragem, ante a multilateralidade do comércio brasileiro, sem delimitar grupos de países. Porém, em razão da grande importância que vem apresentando o grupo BRICS vislumbra-se a utilidade de verificar o grau de coerência entre estas ordens jurídicas, em termos da arbitragem internacional dos contratos internacionais de comércio.

Esta sigla envolve os países em desenvolvimento analisados por Jim O’Neill e que se apresentavam, em 2001, com pujança econômica suficiente para estimular uma reformulação no sistema financeiro mundial. Considerando que o objetivo é alcançar eficiência, parece interessante apresentar uma ressalva com relação aos países insertos na sigla BRIC, especificamente sobre o que se entende por país do sul com relação à Rússia a fim de que seja estimulado o comércio, sem desentendimentos evitáveis, verificando que este país não se percebe nesta condição (JUBRAN: 2014, 174).

Observando que nem sempre o tratamento será o horizontalizado, ficam mais previsíveis como deverão ser conduzidas as tratativas no sentido de dinamizar o comércio. A despeito de ter escolhido a arbitragem como tema específico, parece interessante apresentar, ainda que brevemente, outras nuances envolvidas no comércio.

A resistência dos países com maior participação nos organismos internacionais, especialmente no Fundo Monetário Internacional no qual o direito de voto está atrelado à cota possuída, este grupo de países passa a concertar suas atividades em foros separados. Desta forma, dar maior atenção aos estudos dedicados ao aprofundamento do envolvimento entre estes países, é relevante para o aumento, e diversificação, de suas trocas comerciais.

Não sendo possível uma abordagem mais ampla, a contribuição cingir-se-á a investigar a arbitragem, fenômeno que decorre de controvérsias relativas aos contratos, no caso, internacionais. A solução decorrente do uso de tal instrumento pode aumentar a confiança e segurança jurídica, dinamizando o comércio. Da mesma maneira, pode constituir-se fator desestimulante ante a imprevisibilidade na resolução de controvérsias contratuais entre empresas, ainda mais quando o objeto do contrato é tecnologia. 
Imaginar as possíveis soluções para desentendimentos entre pessoas, jurídicas ou naturais, oriundas de ordens jurídicas soberanas distintas, apresenta grande complexidade e demanda a construção de estruturas estáveis e que transmitamsegurança. É notório que quanto maior for a insegurança, maior será o obstáculo ao comércio de tecnologias.

Há que se ressaltar que o desenvolvimento econômico dos países reduz as vulnerabilidades e desigualdades em suas sociedades. Observe-se que isto decorre tanto da cooperação quanto do comércio, e nestes há possibilidade de ocorrência de divergências. Este estudo debruça-se sobre soluções arbitrais para controvérsias ocorridas em contratos internacionais de comércio. Como se verá, a arbitragem é a forma de solução de dificuldades no cumprimento de contratos internacionais de comércio, por excelência. Assim, o instituto é ampliador de liberdades na medida em que seu bom funcionamento aumenta a segurança quanto às expectativas dos comerciantes, dinamiza o comércio, gerando resultados para os contratantes e para a sociedade em seu conjunto.

A possibilidade de planejamento, por parte dos empresários do setor de tecnologia, preocupados em proteger seus bens imateriais é relevante. A contribuição de uma clara lei de arbitragem pode favorecer a dinamização do comércio neste setor seja por estimular a exportação, seja a importação de tecnologia. Tal fato melhorará o parque industrial que poderá tornar a diversificação do setor secundário sustentável sem causar graves impactos ambientais, por exemplo, o que é benefício direto a toda a coletividade.

Passando ao tema propriamente dito, a arbitragem no Brasil não é instituto novo, porém o estímulo a seu emprego é fenômeno recente. Em razão do aumento da litigiosidade, a integração de novas searas ao direito e o aumento demográfico, o número de processos distribuídos aumentou de tal forma que o Poder Judiciário não consegue atender às demandas complexas com a celeridade necessária.

Nestes termos, a arbitragem ao mesmo tempo em que reduz o número de processos sobre o tema perante o judiciário, também permite que o tema seja analisado por corpo técnico mais afeiçoado ao tema, algo que gera uma celeridade, sigilo e custos compatíveis com as necessidades dos envolvidos.

Por meio de uma perspectiva dedutiva, buscar-se-á pela revisão bibliográfica verificar como a autonomia da vontade quanto à escolha do direito aplicável em uma arbitragem favoreceria os interesses daqueles que transacionam tecnologia além das fronteiras, isto com foco no grupo de países do BRICS. Espera-se poder contribuir para 
a discussão em torno dos benefícios resultantes do reconhecimento, em plenitude, da autonomia da vontade como elemento de conexão essencial para a dinamização docomércio em razão da segurança que passaria aos operadores do comércio internacional de tecnologia.

$\mathrm{O}$ advento da Lei de Arbitragem brasileira, conjugado com a Lei $\mathrm{n}^{\circ} 13.105$ de 16 de Março de 2015 (Novo Código de Processo Civil), expõe possibilidades interessantes tanto sobre a escolha da lei aplicável, quanto em relação à natureza jurídica da sentença arbitral prolatada. Do ponto de vista normativo, a jurisdição brasileira mostra-se adequada à resolução de conflitos decorrentes de contratos internacionais por meio da arbitragem em razão das novas disposições quanto à execução da sentença arbitral. Ressalva feita às disposições constantes na Lei de Introdução às Normas de Direito Brasileiro que cria algumas dificuldades à maior segurança jurídica.

Quando se trata de contratos internacionais de comércio, interessante observar que particularidade diferencia este tipo de avença dos demais, submetidos ao tratamento jurídico de apenas um país. Com relação aos contratos internacionais, objeto das arbitragens internacionais, relevante apresentar a seguinte lição:

Os contratos internacionais, por causa desta característica, desenvolveram
uma especificidade, que os distingue dos que produzem efeitos tão só no
interior de um Estado ou de um mesmo sistema jurídico. Esta especificidade
resultou em certas cláusulas - que atendem a situações típicas de uma relação
econômica ou comercial através das fronteiras, que se tornaram típicas dos
contratos internacionais (BAPTISTA: 2011,17).

A caracterização do contrato internacional decorre da necessidade de identificação do sistema jurídico aplicável aos elementos contratuais seja por conter elementos de estraneidade, seja por ser essencialmente internacional. Também, quando serve de limite à autonomia da vontade em razão da escolha da lei aplicável no momento em que se verifica a conexão com pelo menos dois ordenamentos jurídicos (CÁRNIO: 2009, 13 $-14)$.

A respeito dos elementos de conexão pode-se afirmar que "são expressões legais de conteúdo variável, capazes de permitir a determinação do direito que deve tutelar a relação jurídica em questão" (CÁRNIO: 2009, 16), no caso o contrato internacional. Ainda sobre elementos de conexão, interessante assinalar que são vistos como "aspectos de uma relação jurídica que estabelecem uma ligação com o foro (BAPTISTA: 2011, 33).

Verificando que o estímulo ao uso da arbitragem no Brasil é muito recente, interessante apresentar como o instituto está delineado no MERCOSUL, a fim de 
verificar se a estrutura disponibilizada com o fito de preservar a harmonia entre este organismo e o BRICS.

Por derradeiro, espera-se que deste trabalho seja possível um fomento ao debate com o fito de tornar a Arbitragem Brasileira, com relação aos contratos internacionais, uma alternativa interessante aos operadores do comércio internacional entre BRICS. Isto a fim de apresentar a arbitragem internacional brasileira como fator relevante no momento da contratação com empresas nacionais, em razão da previsibilidade e segurança sobre o conteúdo de uma sentença arbitral. Importante ressaltar que este meio para solucionar controvérsias é adequado às opções que o Brasil tem de expansão comercial em âmbito multilateral.

\section{A ARBITRAGEM INTERNACIONAL}

O Brasil passa a dar maior importância à arbitragem internacional somente quando por intermédio do Decreto $\mathrm{N}^{\mathrm{o}} 4311$ de 23 de julho de 2002, ratifica, incorporando ao ordenamento jurídico pátrio a Convenção de Nova Iorque sobre reconhecimento e execução de sentenças arbitrais estrangeiras de 10 de junho de 1958.

Enquanto internamente muito se discute sobre em que searas do direito seria possível a resolução pela arbitragem, certo é que em se tratando de contratos internacionais de comércio, até pela familiaridade do empresariado estrangeiro, nos países do BRICS ela é o meio mais recomendado devido às vantagens da celeridade e sigilo e expertise dos árbitros. Além das disposições inscritas na Lei Modelo da UNCITRAL, a arbitragem e o seu uso no plano internacional, pode ser observada na seguinte perspectiva:

No plano internacional, a arbitragem foi ao longo de séculos a única jurisdição conhecida: sua prática remonta, no mínimo, ao tempo das cidades gregas. Mas da arbitragem diz-se, com acerto, que é um mecanismo jurisdicional não judiciário. Isso porque o foro arbitral não tem permanência, não tem profissionalidade (REZEK: 2015, 395).

Sabendo que os países integrantes do grupo BRIC são signatários da Convenção de Nova Iorque sobre arbitragem, nota-se que em boa medida há aproximação, ainda que indireta, de suas ordens jurídicas sobre o tema. A instituição de um banco próprio tende a aproximar-lhes em termos comerciais, o que torna relevante uma aproximação entre suas regras de direito internacional privado, principalmente sobre $\mathrm{o}$ reconhecimento expresso da autonomia da vontade como elemento de conexão, e sobre arbitragem de contratos internacionais de comércio de tecnologia. Tornar os enlaces 
contratuais mais confiáveis e estáveis, do ponto de vista jurídico, confere maior segurança aos comerciantes. Assim, a estabilidade quanto às expectativas em relaçãoaos contratos internacionais sobre tecnologia, notadamente quando houver controvérsias, é fator de grande importância para o cômputo dos envolvidos em suas disposições de contratar. Nestes termos, alterar a Lei de Introdução às Normas de Direito Brasileiro de maneira a harmonizar-se à Lei 9307/96, para o Brasil, é medida imprescindível para o alcance desta finalidade. Esta posição não é muito diferente do que se pode observar na doutrina, neste sentido:

\begin{abstract}
Às partes incumbe a escolha do árbitro, a descrição da matéria conflituosa, a delimitação do direito aplicável. $\mathrm{O}$ foro arbitral não tem permanência: proferida a sentença, termina para o árbitro o trabalho judicante que lhe haviam confiado os Estados em conflito (REZEK: 2015, 396).
\end{abstract}

A liberdade com relação à escolha do direito aplicável, observadas as limitações decorrentes da ordem pública, interesse público e fraude à lei, favoreceria o comércio com o Brasil. Assim, mostra-se oportuna esta apresentação.

A vigência do Novo Código de Processo Civil que, expressamente, consagra a sentença arbitral como título executivo judicial é circunstância que, conjugada ao reconhecimento pleno da autonomia da vontade, com relação aos contratos internacionais, extinguiria a antinomia ainda presente e levaria maior estabilidade à seara do comércio internacional de tecnologias.

\title{
2. A ARBITRAGEM INTERNACIONAL DE CONTRATOS INTERNACIONAIS DE COMÉRCIO NOS BRIC
}

Com relação aos países componentes do BRIC (Brasil, Rússia, Índia e China), é sabido que não há problemas quanto ao uso da arbitragem para a solução de controvérsias entre pessoas jurídicas de direito privado. Com relação ao Poder Público, a Lei 13.129/15, que alterou a Lei 9307/96 franqueou o uso da arbitragem para contratos envolvendo o Estado. Frise-se que, neste caso, incidirá o princípio da publicidade a fim de possibilitar o controle social.

Nos contratos firmados entre empresas, no que diz respeito ao uso da arbitragem, na convenção de arbitragem não pode haver cláusulas que avancem sobre temas indisponíveis à livre disposição pelas partes. Também deve ser clara a redação quanto ao objeto a ser submetido, aos limites de atuação do árbitro, à lei aplicável e concebida com atenção para a capacidade jurídica das partes em celebrar tal ato, imprescindível à 
instalação da arbitragem. Estas exigências são verificáveis em todos os países do grupo BRICS.Com relação aos casos que envolvem a iniciativa privada e o poder público é verificável que tem sido implementado o uso da arbitragem para a resolução de controvérsias contratuais. Todavia o inconveniente decorrente do uso das limitações possibilitadas pela vagueza do que viria a ser ordem pública e interesse público são prejudiciais ao seu uso adequado. Não há como inspirar segurança na iniciativa privada quando o Poder Público pode utilizar tal argumento para fugir ao cumprimento do disposto na sentença arbitral. Este problema afetará todos os países do grupo.

Vale ressaltar que o interesse público ou ordem pública podem vir a impedir a instalação da própria arbitragem, como é possível verificar da seguinte passagem:

\begin{abstract}
Outro ponto que deve ser abordado neste momento do trabalho é o fato de que, no que concerne à arbitragem comercial internacional, não existem matérias específicas que sejam apontadas, por quaisquer das legislações em debate, como não arbitráveis. O limite para a arbitragem comercial internacional reside tão somente, nos casos de Brasil, Rússia e Índia apenas nas questões relevantes à "ordem pública" e, na China, ao que se denomina "interesse público" (FREIRE: 2014, 42).
\end{abstract}

Assim, a segurança quanto à previsibilidade da solução de um conflito relacionado a um contrato internacional de comércio pode erodir a confiança e prejudicar a celebração de contratos. Basta ao leitor imaginar como esta insegurança pode afetar negativamente a celebração de contratos de transferência de tecnologia.

Outro ponto que merece atenção é a arbitrabilidade. Aqui também há evidente diferença de tratamento jurídico entre os países, valendo frisar que o Brasil é onde a legislação tem procedimento mais prático quando debruça-se com mais atenção à nacionalidade da sentença arbitral e não à arbitragem em si (FREIRE: 2014, 43).

No Brasil o reconhecimento da autonomia da vontade de forma expressa pela Lei 9307/96 e seu não reconhecimento pela Lei de Introdução às Normas de Direito Brasileiro, importa em antinomia que gera resultados não muito produtivos, como se pode ler:

O tema referente à lei aplicável em matéria de contratos internacionais não é a única preocupação com relação à autonomia das partes. Também com relação à escolha do juízo competente para julgar a causa há problemas, como se verá da análise da jurisprudência. A regulamentação das hipóteses de competência internacional no Brasil está no Código de Processo Civil, nos artigos 88 a 90, que trata, de forma ampla, das hipóteses de sua ocorrência exclusiva e concorrente. No caso da jurisdição concorrente, onde há a possibilidade de escolha de foro, prevê a lei a possibilidade de que outros países conheçam da mesma lide, não impossibilitando o juiz brasileiro de também conhecê-la. Mas nos casos em que a escolha recaiu sobre a justiça estrangeira, muitas vezes o juiz nacional não abriu mão da possibilidade de 
julgar a causa, tornando a cláusula sem efeito. Apesar de, no âmbito do Mercosul, essa eleição ser expressamente permitida pelo Protocolo de Buenos Aires sobre jurisdição internacional em matéria contratual, sua utilização pelo Judiciário brasileiro é mínima. (ARAÚJO; JACQUES: 2008, 269)

Para dimensionar o problema, basta verificar que o Art. $2^{\circ}$ da Lei 9307/96, prevê a livre escolha das regras de direito aplicáveis à arbitragem, inclusive princípios gerais, usos e costumes do comércio internacional, com as limitações decorrentes dos bons costumes e ordem pública.

Já Lei de Introdução às Normas de Direito Brasileiro, no que diz respeito aos contratos internacionais, exatamente em relação aos quais pode vir a ocorrer a arbitragem internacional, estabelece a aplicação da lei do país onde for constituída a obrigação ou a lei brasileira caso a execução deva ser realizada no país, além do fato de considerar a obrigação constituída no local de residência do proponente.

A falta de clareza pode levar o Poder Judiciário Brasileiro a imiscuir-se nas relações contratuais e dar uma interpretação que afronta diretamente o interesse da parte. Isto em um contrato parece não gerar muito problema. Entretanto, ao refletir sobre o efeito negativo sobre a disposição dos comerciantes a sujeitar-se a tamanha vulnerabilidade, afigura-se como sendo uma questão a ser debatida. A utilização da Lei Modelo da UNCITRAL trouxe boas soluções para os que transacionam além fronteira, todavia ainda são necessárias mais algumas adequações.

A fim de ratificar a antinomia na ordem jurídica brasileira sobre a autonomia da vontade como elemento de conexão, iniciando por observar seu reconhecimento pelo mundo:

O direito das partes num contrato internacional de escolher a lei aplicável ao mesmo é aceito quase que universalmente. Nygh, acompanhado por Jayme e Van Loon, sugere uma base jurídica calcada em direitos humanos. É aceito pelas diversas legislações e reconhecido também por tribunais arbitrais (BAPTISTA: 2011, 48).

Em outra paragem, é possível verificar a deformação da autonomia da vontade o que torna seu conteúdo semântico esvaziado, neste sentido:

\begin{abstract}
A opinião de parte da doutrina no Brasil é de que - salvo a predominância da lei brasileira no que tange à forma, e sua aplicação imperativa nos contratos relativos a imóveis - a regra é a da autonomia da vontade, à qual se podem opor, afastando-a, as leis imperativas do foro e a ordem pública internacional. Entretanto, como se viu mais atrás, não é essa corrente doutrinária a predominante, mas sim a da aplicação indireta do "princípio da autonomia" pela escolha do local de contratação (BAPTISTA: 2011, 50).
\end{abstract}

Feitas estas observações, interessante observar a desarmonia entre as regras dos países BRIC relativas à convenção de arbitragem. Enquanto os demais países utilizando 
a convenção de arbitragem delimitam todos os elementos autorizadores de suainstauração, o Brasil separa a convenção de arbitragem do compromisso arbitral, sendo esta autônoma em relação ao contrato ao qual está atrelada, preservando seus efeitos mesmo na hipótese de nulidade do contrato.

Neste caso da realidade brasileira, por intermédio do compromisso arbitral, as partes concordam em submeter os dissensos decorrentes da relação contratual à solução arbitral. Vale notar que por vezes, em razão do princípio da inafastabilidade do judiciário vigente na ordem jurídica brasileira, o Poder Judiciário termina imiscuindo-se em relação jurídica que deveria ter seus dissensos resolvidos por arbitragem. Tal fato torna o judiciário mecanismo para tentar frustrar compromisso firmado com base na autonomia da vontade, algo que gera insegurança quanto à solução de controvérsias e levanta fortes dúvidas entre os comerciantes.

Com relação à convenção de arbitragem (ou compromisso arbitral), esta significando a delimitação do objeto, lei aplicável, escolha do árbitro, entre outros aspectos, pode ser obtida perante o juízo nos termos do Art. $7^{\circ}$ da Lei 9307/96 ou pela via extrajudicial, obedecida a regra constante no Art. 10 do mesmo diploma.

Este tratamento diferente, não parece muito adequado quando o propósito do mecanismo multilateral que lhe deu origem visa a aproximar e dinamizar as relações comerciais entre os países signatários. Assim, catalisar o comércio com os demais BRICS é também harmonizar as regras jurídicas:

\begin{abstract}
A harmonização jurídica pode ser compreendida em sentido amplo e estrito. No sentido amplo, assume o significado de aproximação jurídica e relacionase com a utilização de mecanismos para aproximação do direito em maior ou menor grau, comportando três subcategorias: harmonização propriamente dita, uniformização e unificação do direito. Em sentido estrito, a harmonização configura-se pelo emprego de mecanismos específicos que visam apenas alinhar determinados ordenamentos: não há a necessidade de direito idêntico, apenas coerente (FIALHO: 2008, 24).
\end{abstract}

O Brasil bem adequou sua ordem jurídica às novas necessidades decorrentes do aumento do comércio internacional ao criar a Lei 9307/96, baseada na Lei Modelo da UNCITRAL. Todavia, permanece a necessidade de superação do problema relativo à antinomia entre a Lei de Arbitragem e a Lei de Introdução às Normas de Direito Brasileiro com relação à escolha do direito aplicável. Com relação ao foro, o país reconhece a arbitragem instituída ad hoc.

A Rússia e Índia possuem regras mais estáveis sobre escolha do foro, reconhecendo inclusive a arbitragem ad hoc, bem como a escolha do direito aplicável 
aocaso por parte dos contratantes, com as limitações decorrentes da necessidade de proteção à ordem pública e fiscalização de possível fraude à lei.

Com relação à China, a ressalva é feita com relação à arbitragem $a d$ hoc, não reconhecida por sua legislação. Nestes termos, a arbitragem realizada no estrangeiro e que necessite execução em território chinês ficaria prejudicada na hipótese de não ter sido realizada perante tribunal arbitral.

\section{O BRASIL E O INTERESSE PÚBLICO: como esta limitação pode afetar a incidência do Art. $2^{\circ}$ da Lei 9307/96}

É possível formular um raciocínio interessante, tomando por base a proximidade do início da vigência do Novo Código de Processo Civil, que ratifica a natureza de título judicial à sentença arbitral.

Vale consignar que a arbitragem internacional pode, nos termos da Convenção de Nova Iorque, vigente no país, ser realizada sob a ordem jurídica brasileira ou em terras estrangeiras. Ante a falta de tratamento mais preciso na Lei 9307/96, há que se estremar a arbitragem internacional, descrita na Convenção ratificada pelo Brasil em 2002, da arbitragem internacional realizada sob a jurisdição de outro Estado soberano.

Considerando que a arbitragem internacional pode vir a ser estabelecida em território pátrio e que o novo código de processo civil considera a sentença arbitral como título judicial, salvo melhor juízo, parece razoável concluir que a autonomia da vontade terá reforço na sua caracterização como elemento de conexão. Isto em razão de observação de posicionamentos do STJ com relação a homologação de sentenças arbitrais estrangeiras.

Isto porque o entendimento é de que não reaprecie o mérito da arbitragem em sede de procedimento de homologação de sentença de arbitragem internacional (SEC 11969 / EX SENTENÇA ESTRANGEIRA CONTESTADA 2014/0122435-7. STJ 16/12/2015). Nestes termos, não há dúvida de que tal consequência deva servir para o cumprimento de sentenças de arbitragens internacionais realizadas sob competência de árbitro com sede no Brasil.

Passando a uma reflexão no âmbito dos BRICS, interessante ressaltar que outros países do grupo BRICS, em suas ordens jurídicas, tiveram a preocupação em diferenciar as arbitragens internas das internacionais. Vale demostrar alguns dos pontos específicos de cada um dos países.

A Índia, por exemplo, estabelece que o contrato deve ser entendido como comercial nos termos de sua legislação, inclusive indicando quais atividades não tem tal 
atributo. Difere a arbitragem internacional da interna pelo critério territorial, bastando que uma das partes seja residente, ainda que temporariamente, em outro país. Há que se observar a inexistência de preocupação quanto aos efeitos deste enlace contratual e local de celebração, bastará ser o contrato comercial e uma das partes não residir, ao menos, no país (FREIRE: 2014, 41).

$\mathrm{Na}$ Rússia a legislação consigna às partes o direito de escolher a lei aplicável, além de aplicar os costumes do comércio incidentes sobre a transação objeto da arbitragem (YURYEV; KANTYREV: 2012, 671, 672). Também, vale ressaltar que quando uma das empresas russas tenha realizado ou recebido investimento estrangeiro, a arbitragem também será considerada internacional (FREIRE: 2014, 41-42).

$\mathrm{Na}$ legislação indiana, em sede de contratos internacionais, é franqueado às partes o direito de escolha da lei aplicável desde que indicada expressamente. Também é possível às partes que permitam ao árbitro que escolha a lei ex equo et bono (Misra; Kapoor: 2012, 440)

Por sua vez, a legislação chinesa desconhece a definição de elementos estrangeiros em seus contratos. Ainda assim admite a escolha da lei aplicável desde que nos limites impostos pela lei interna (GLÜCK; LIECHTENSTEIN: 2012, 223). Da mesma forma, não define o que seria arbitragem internacional e tende a aplicar a lei doméstica nos casos em que o árbitro ou tribunal arbitral tenha sede chinês, porém reconhece as sentenças arbitrais oriundas de outras ordens soberanas contra seus nacionais (FREIRE: 2014, 42).

Feitas estas considerações, parece adequado que sejam realizados estudos sobre a caracterização da arbitragem internacional nas ordens jurídicas domésticas de cada país. A medida visa a evitar confusões desnecessárias e que possam levar à perda de dinamismo nas relações comerciais em razão da falta de estabilidade decorrente da desarmonia jurídica, resultado da incoerência do tratamento dispensado a tema tão relevante.

\section{O EXERCÍCIO DA AUTONOMIA DA VONTADE COMO INTERESSE PÚBLICO}

A Constituição Brasileira prevê expressamente a autonomia da vontade ao proteger a livre iniciativa. Salvo melhor juízo, observando que nos contratosinternacionais de comércio, os agentes, via de regra, não celebram contratos de 
adesão, mas contratos bilaterais e sinalagmáticos, imperativo seria reconhecer a possibilidade de ser possível indicar, expressamente e nos termos da nossa lei, que lei material deveria ser aplicada pelo árbitro no procedimento a si submetido.

Porém, muitas vezes há alegação perante o Poder Judiciário, normalmente aventado pela parte descumpridora do contrato de ofensa ao interesse público. Isto na busca do esvaziamento do conteúdo da sentença levando a frustração à contraparte. Ao pensar egoisticamente, não age de forma equivocada a parte, porém dependendo do argumento apresentado pelo juízo a fim de deferir tal pedido, pode estar o mesmo restringindo o desenvolvimento econômico, a liberdade e deixando vulneráveis os consumidores. Ao frustrar as expectativas daqueles que contratam com a iniciativa privada brasileira, ou Poder Público, não é absurdo pensar que isto reduzirá a disponibilidade de produtos em determinado seguimento o que, fatalmente, levará a uma distorção nos preços.

Mais grave ainda, pensando que o desenvolvimento tecnológico, levado a efeito pela iniciativa privada, é realizada via contrato e que nestes há a previsão de utilização da arbitragem como meio de solução de conflito, considerando que a tecnologia, objeto da lide, demanda toda proteção possível e o sigilo da arbitragem atende a esta necessidade, a inadvertida intervenção do magistrado, não especializado na área, pode causar um quebra de confiança que levará a não transmissão do conhecimento. Observando que o Brasil é um país que busca o desenvolvimento na modalidade sustentável, mas que este ainda está sendo construído justamente por meio da tecnologia que se vem desenvolvendo em processos de cooperação e em aquisições internacionais de tecnologias, o funcionamento da arbitragem de modo adequado e em atenção à máxima autonomia da vontade, obviamente sem desconsiderar as vedações sobre fraudes à lei, deve ser efetiva.

Quanto ao interesse público, este muitas vezes utilizado como válvula de escape para limitar o exercício da liberdade, o que pode ser considerado como sendo um atentado. Para ser realizada tal intervenção deveriam ser fixados critérios claros, de preferência via legislação, caso o aplicador fosse o magistrado, ou casuisticamente, caso fossem especialistas quanto ao objeto do contrato.

Para atestar que o interesse público, como apresentado e manejado, não se mostra apropriado a servir de barreira à execução das sentenças arbitrais, construídas emconformidade com os desígnios das partes que, no comércio internacional, apenas utilizam seus direitos disponíveis, lê-se o seguinte: 
O interesse público é um postulado ético-político. Frequentemente apresentado como pressuposto da ordem social, ele é visto como a realização da vontade geral, entregue a um ser externo a todos os indivíduos - o Estado - encarregado da sua realização. Sua validade não depende de qualquer positivação, vai existir mesmo se o ordenamento jurídico não o trouxer em qualquer previsão. Ao mesmo tempo ele é fruto da observação, da experiência.

$\dddot{\mathrm{O}}$ postulado é obtido do senso comum e permite o conhecimento do fenômeno jurídico, da lei. Ele não pode, por si, fundamentar a decisão, mas sim explicar como pode ser obtido o conhecimento do Direito. Por isso, está sempre atrelado ao interesse público uma justificativa, a explicação de como ele é interpretado naquele contexto ou momento. Esta explicação pode e deve ser positivada, sobretudo em um contexto multilateral, para que não se torne desculpa para a discricionariedade acima referida, inviabilizando, assim, a aplicação do referido instrumento (antidumping). (Cordovil, 2011, 100 101)

A despeito das referências ao antidumping, tema deveras relevante, a compreensão sobre o conteúdo da expressão interesse público é extensível às demais relações, inclusive para a arbitragem, quando se há clara limitação da autonomia da vontade. Não há como os agentes privados fazerem previsões sobre os resultados de seus contratos internacionais. Como saber se os termos do contrato serão reconhecidos e a sentença arbitral terá sua execução levada a efeito? Pode surgir, de surpresa, um argumento impeditivo a tal cumprimento forçado, vazado no interesse público, sendo que este será construído naquele momento e normalmente com base no senso comum. Por isso a preocupação com a insegurança. Delegar tal exame a corpo de profissionais especializados no ramo, ou disciplinar juridicamente afigura-se mais adequado. Tanto maior for a previsibilidade e a estabilidade, maior dinamismo terá a atividade econômica, geradora de tantos benefícios. Dar maior precisão ao interesse público, e tratamento mais adequado, é amplia a liberdade e reduzir a vulnerabilidade. É possível proteger os interesses do Estado sem travestir interesses privados de pequenos grupos em tal limitação ao exercício da autonomia.

Um aspecto ligado ao comércio internacional é a concorrência, algo imprescindível ao desenvolvimento econômico e à melhoria das alternativas de consumo para as populações. Ao tratar do conflito de lei, alerta para o fato de que a política interna de concorrência deve ser utilizada nos processos em atenção à ordem jurídica interna a fim de que haja a harmonização dos interesses da iniciativa privada às previsões do direito brasileiro. Por oportuno, apresenta a distorção que significa a utilização, pelo CADE, de argumentos utilizados por autoridades estrangeiras paradecidir questões que afetam a concorrência na esfera doméstica. Tal expediente por gerar graves prejuízos, tendo em vista que não se há como decidir concorrência 
desleal no Brasil tomando por base, por exemplo, a realidade norte-americana. (FORGIONI:

2012, 423-440)

É nítido que a melhor forma de garantir o desenvolvimento econômico e sustentável, passa por ampliar as liberdades, inclusive a de escolha. Esta será tão ampla quanto for clara a previsibilidade quanto ao resultado de um contrato em todas as suas possibilidades, inclusive o descumprimento. A legislação de concorrência, uma forma de garantir a livre iniciativa, é uma maneira pela qual o interesse público de garantir a liberdade é descrita em texto de lei. Melhor seria que o interesse público fosse, o máximo possível, reduzido a regra, independente da perspectiva em que se pretende proteger direitos fundamentais, que deveriam ser a base para tal abordagem.

Afigura-se bom limitador para o exercício da autonomia da vontade quanto ao conteúdo dos contratos internacionais de comércio, bem como das convenções de arbitragem, o controle da fraude à lei. Observando-se que o interesse público, a fim de ser mais palpável seria convertido em enunciado válido, vigente e eficaz, ou seja, dotado de coercitividade, razoável que os direitos fundamentais fossem molde para a construção normativa do interesse público.

Tudo na intenção de conferir maior segurança aos cálculos dos empresários que operam no comércio internacional, pensando que a maior segurança jurídica seja um dos fatores de dinamização comercial, ou entrave no sentido oposto.

\section{A AMPLIAÇÃO DA LIBERDADE NOS CONTRATOS INTERNACIONAIS DE COMÉRCIO: o desenvolvimento}

A busca pelo desenvolvimento exige a articulação de vários setores do conhecimento, inclusive do Direito. Neste, há vários ramos que bem harmonizados, podem aumentar a liberdade e promover o desenvolvimento, este consistente na busca do bem-estar social.

Uma busca efetiva pelo desenvolvimento só poderá ser realizada com a ampliação da liberdade que, por sua vez implicará aquisição e aumento das responsabilidades, a fim de que seja preservado o exercício da autonomia da vontade (SEN: 2010, 360-361) e, dará mais segurança aos procedimentos arbitrais, objeto deste estudo.

A razão é que ao conceder a liberdade ao agente econômico para fazer suas escolhas e ser responsabilizado por elas, necessariamente fará com que, por 
necessidadede preservação, ajuste suas expectativas às possibilidades jurídicas, incluindo a sustentabilidade, que dever ser disciplinada juridicamente e de modo claro.

Desta forma, ao invés de ser assistencialista com aqueles que, livres, resolvem celebrar contratos que podem lhes trazer malefícios, o Estado pode dedicar seus esforços para levar a liberdade àqueles que se encontram em posição de vulnerabilidade, como se pretende evidenciar, dentro do restrito limite deste despretensioso trabalho.

Parece adequado assinalar que o desenvolvimento decorre não somente da acumulação de capital em virtude do comércio, mas também da aquisição de tecnologia para o ganho de eficiência que reduzirá custos de produção e importará em ampliação de opções à população. Assim, o comércio de tecnologias é ferramenta apropriada para este fim, porém este processo deve ser favorecido de maneira a evitar protecionismo por parte dos agentes econômicos. A livre concorrência deve ser estimulada a fim de que sejam obtidos resultados benéficos, valendo a seguinte análise:

A evolução do conceito de desenvolvimento tornou-o mais complexo, ao
acrescentar as variadas dimensões ligadas às relações sociais, políticas,
econômicas, culturais, tecnológicas, de forma a finalmente incluir uma
variável qualitativa de sustentabilidade que assegure um patamar
diferenciado de bem-estar social. O que significa um exercício mais efetivo
da liberdade, que implicaria em maior concretização da igualdade, em um
ambiente sadio e ecologicamente equilibrado (ANDRADE: 2005, 341).

Outro efeito da falta de tecnologia, além da concentração de riqueza, é a degradação do meio ambiente. Isto se deve ao fato de que para sobreviver, passam a explorar o solo para o plantio por meio de expedientes rudimentares envolvendo a derrubada de florestas, queimadas a fim de expandir a área de cultivo com baixa produtividade, o que demandará vastas áreas. Aliado ao fato de que as nações desenvolvidas, mesmo com melhores tecnologias, também superexploram o ambiente, só que com maior produtividade, o resultado beira a catástrofe (ANDRADE: 2005, 333).

A importância do estímulo à transferência de tecnologia é a possibilidade de que esta seja difundida entre os setores produtivos. Garantir a estabilidade das expectativas dos envolvidos no comércio é passo importante para a dinamização. Isto pode ser viabilizado por uma maior liberdade na escolha do direito aplicável, bem como na escolha do foro competente com relação aos contratos internacionais.

Pensando na arbitragem, para ilustrar, o reconhecimento da autonomia da vontade no momento da contratação representa segurança quanto ao resultado de solução de 
controvérsia. Esta maior liberdade estimulará os agentes a negociar melhor os termos afim de evitar prejuízos em razão de não poderem buscar no judiciário uma forma de descumprir tanto o contrato quanto a sentença arbitral. Vale observar que é esta conduta das partes em se furtar ao cumprimento da sentença arbitral por meio dos poderes judiciários de seus países que terminam por levar a insegurança ao comércio internacional. Nestes termos, as normas devem ser claras no sentido de estabelecer limites objetivos à intromissão do poder judiciário em dissensos surgidos em contratos internacionais de comércio.

Retornando ao tema do desenvolvimento, Amartya Sen, descreve as condições nas quais é possível vincular a liberdade à responsabilidade. No presente estudo, que versa sobre comércio internacional, tema que envolve contratantes bem aquinhoados e, por isso, livres, é possível atribuir a eles a responsabilidade, nestes termos:

Uma divisão de responsabilidades que ponha o fardo de cuidar do interesse
de uma pessoa sobre os ombros de outra pode acarretar a perda de vários
aspectos importantes como motivação, envolvimento e autoconhecimento
que a própria pessoa pode estar em condição única de possuir. Qualquer
afirmação de responsabilidade social que substitua a responsabilidade
individual só pode ser, em graus variados, contraproducente. Não existe
substituto para a responsabilidade individual (SEN: 2010, 360-361).

Esta passagem pode ser aplicada àqueles que já disponham de sua liberdade. A estes não cabe proteção superior, neste caso, dada pelo Estado, tendo em vista que já livres, devem ser responsáveis por seu próprio progresso, ou pelo seu declínio.

De modo diverso, por exemplo, deveria ser visto o consumidor, hipossuficiente e carente de plenitude em sua liberdade. Neste caso, cabe ao Estado agir para garantir que ele tenha condições de poder desempenhar sua liberdade a fim de que possa arcar com seus encargos ou responsabilidades.

Isto pode ser visto em uma arbitragem. Por exemplo, o Judiciário quando nega um exequatur visando a proteger um determinado comerciante que, usando sua liberdade, firmara contrato em relação ao qual sabia da impossibilidade de descumprimento, termina por causar distorção desnecessária. Esta medida afetará negativamente o setor, em razão da desconfiança decorrente desta inadequação, reduzirá a liberdade de outras pessoas, inclusive as mais vulneráveis. Eis mais um motivo para o respeito à arbitragem: garantir a segurança jurídica tanto ao preservar a expectativa do credor quanto ao impor ao agente econômico livre que arque com a responsabilidade que lhe cabe em razão do empreendimento ruinoso no qual ingressou espontaneamente. Vale mais uma transcrição, agora sobre a forma de atuar do Estado, como se segue: 
A alternativa ao apoio exclusivo na responsabilidade individual não é, como às vezes se supõe, o chamado "Estado babá". Há uma diferença entre pajearas escolhas de um indivíduo e criar oportunidades de escolha e decisões substantivas para as pessoas, que então poderão agir de modo responsável sustentando-se nessa base (SEN: 2010, 362).

Desta forma, reduzir desigualdades e ampliar o bem-estar têm relação com o reconhecimento da autonomia da vontade no comércio internacional.

\section{A ARBITRAGEM INTERNACIONAL INTERNA: a nova possibilidade} decorrente de disposição contida na codificação processual civil

O início de vigência do Novo Código e Processo Civil resulta no reconhecimento da sentença arbitral como título executivo judicial. Com isto, é interessante uma reflexão sobre a autonomia da vontade na escolha do direito aplicável.

Considerando não haver dificuldades com relação à arbitragem interna, aquela envolvendo nacionais e submetidas à ordem jurídica brasileira, interessante tratar das arbitragens que atraem, com relação ao direito material, regras oriundas de ordens jurídicas distintas. Nestes casos, a observação dos elementos de conexão, à luz das regras de direito internacional privado vigente, seriam suficientes para a indicação do direito aplicável. Porém o direito brasileiro não é plenamente claro sobre o reconhecimento da autonomia da vontade com relação ao direito aplicável, notadamente em razão da antinomia entre a LINDB e a Lei 9307/96.

Partindo-se do pressuposto que grande preocupação dos Estados, com relação às arbitragens internacionais, esteja centralizada na escolha do direito material aplicável, é que se afigura importante uma melhor delimitação do que seria arbitragem internacional, ainda mais no Brasil cujo novo código processual estabelece que a sentença terá natureza de título executivo judicial.

Vale frisar que a não concessão do exequatur na Lei de Arbitragem é dirigida às arbitragens estrangeiras, ou seja, àquelas realizadas sob os auspícios da ordem jurídica de algum outro Estado soberano.

Ao ser convocado a pronunciar-se sobre arbitragens internacionais, deve o Poder Judiciário, responsável pelo cumprimento da sentença arbitral, ter ciência da importância do tratamento dispensado aos contratos internacionais de comércio. Isto considerando que seu posicionamento por afetar positiva, ou negativamente, a disposição de contratar. Assim, vale o apontamento: 


\begin{abstract}
A determinação da sede da arbitragem é muito importante posto que pode influenciar no decorrer do processo arbitral, no custo da arbitragem, na execução das decisões arbitrais proferidas e em muitos outros aspectos de grande relevância ao resultado da arbitragem, dependendo também das disposições de lei de cada país (FREIRE: 2014, 55).
\end{abstract}

Com relação a este ponto, parece estar superado no Brasil problemas relativos à possibilidade de judicialização de controvérsias decorrentes de contratos para os quais houve a opção da arbitragem tendo em vista que a jurisprudência entende que é inviável discutir em juízo contratos para os quais as partes optaram pela via arbitral (RECURSO ESPECIAL No 712.566 - RJ (2004/0180930-0). STJ. 18/08/2005).

Mostra-se adequado, ainda que de modo breve, fazer alguns apontamentos sobre a autonomia da vontade quanto à escolha do direito material a ser utilizado como substrato para a decisão do árbitro. Isto em razão de tal atividade poder ser realizada no estrangeiro ou no Brasil, valendo atentar para o fato de que se deve transmitir segurança sobre a efetividade do cumprimento da regra, bem como transmitir qual deva ser sua adequada compreensão.

Mereceria debate a possibilidade de uma sentença arbitral exarada no Brasil, em razão de arbitragem internacional, poder ter sua execução frustrada mesmo com a vigência do Art. 515, Inc. VII, sob o argumento de que a sentença ofenderia a ordem jurídica nacional, apesar de ter sido produzida aqui. Ao que tudo leva a crer, tomaram arbitragem estrangeira por arbitragem internacional e elas são essencialmente distintas.

A intenção é de que a arbitragem internacional realizada no Brasil, por via transversa, não termine sendo afetada pelas disposições referentes às sentenças arbitrais estrangeiras, o que esvaziaria o conteúdo da regra estabelecida pela nova codificação processual civil além de levar insegurança jurídica ao comércio internacional. Como consequência, haveria prejuízos a toda sociedade de consumo o que resultaria em redução de suas liberdades de escolha e do ganho de benefícios resultantes da concorrência ao viabilizar a competição e suas benesses como, por exemplo, a melhoria nos preços.

\title{
CONCLUSÃO
}

É sabido que para reduzir as vulnerabilidades e promover o desenvolvimento, é necessário estudo multidisciplinar para que sejam buscadas soluções adequadas aos entraves encontrados. Neste caso, a maior segurança quanto ao tratamento jurídico 
dispensado para os casos nos quais existam controvérsias relativas aos contratos internacionais versando sobre tecnologia seria um componente favorável à dinamização destas relações o que favoreceria o setor industrial de modo geral.

Dentro de uma ideia de uma cooperação mais horizontalizada, sem condicionalidades e com benefícios mútuos, apresentou-se o grupo BRICS, que tem seaproximado, como alternativa para o desenvolvimento do Brasil. Interessante que as potencialidades sejam aproveitadas mutuamente a fim de suprir suas demandas por tecnologias e conhecimento. Com isto poderiam produzir suas próprias inovações, estas apropriadas às suas realidades.

Optou-se por estudar a autonomia da vontade quanto à escolha da lei aplicável e do foro, elementos importantes para a realização da arbitragem internacional, meio de solução de controvérsias amplamente usado para resolver dissensos em contratos internacionais de comércio, estes de grande relevância para a aquisição de tecnologias produzidas em outros países. Observando que na ocorrência de divergências, a solução destes é buscada por meio da arbitragem internacional, relevante que este instituto esteja conformado de maneira a servir como catalisador e não como entrave ao comércio em setor produtivo tão sensível à insegurança.

Visualiza-se a ocorrência de inadequações no tratamento jurídico dispensado ao instituto, a nível processual, em todos os países da sigla. Com relação ao Brasil, no qual o estudo foi um pouco além, é possível verificar que a limitação ao exercício da autonomia da vontade nos contratos internacionais de comércio, decorrente do princípio do interesse público, não é dotado de conteúdo semântico estável e favorável ao exercício das liberdades contratuais. Esta limitação importa em insegurança que é fato de desestímulo ao comércio. Quanto maior a previsibilidade em relação ao atendimento das expectativas, mais dinâmico o comércio. No Brasil, apesar de uma legislação avançada em termos de arbitragem, falta aprimorar os elementos de conexão, notadamente a autonomia da vontade.

Também, ao apartar a arbitragem internacional da estrangeira, não parece claro o conteúdo semântico do que viria a ser a sentença arbitral qualificada como título executivo judicial no Código Processo Civil, prestes a entrar em vigor. Não há que dificuldades enfrentará o dispositivo, não com relação às arbitragens domésticas, mas quanto às arbitragens internacionais realizadas no país, em razão da aplicação da Lei de Introdução às Normas de Direito Brasileiro, que limita a autonomia da vontade. 
Assim, a falta de disposições normativas claras sobre a arbitragem internacional, bem como comportamento vacilante do poder judiciário ao ser convidado a tratar do tema não são elementos favoráveis ao resultado esperado no processo de internacionalização da economia brasileira. A limitação indevida da autonomia da vontade das partes cria uma insegurança que torna desaconselhável a celebração de contratos internacionais sobre transferência de tecnologia em razão da imprevisibilidadequanto ao encaminhamento a ser dado na hipótese de ocorrer controvérsias em relação á avença celebrada.

A arbitragem, na hipótese de ter assegurada a autonomia da vontade para a escolha da lei aplicável e do foro, torna-se instituto apto à dinamização do comércio internacional de tecnologia.

Assim, é imprescindível a supressão das restrições à autonomia da vontade aos contratantes com origem nos países do BRICS. No caso brasileiro, necessário é que seja cumprida a lei 9307/96, bem como seja alterada a Lei de Introdução às Normas de Direito Brasileiro de maneira que não reste dúvidas tanto em relação à liberdade de escolha de direito aplicável quanto em relação à escolha do foro. Com relação à China, feitas as alterações nas regras brasileiras, seria prudente que os contratantes nacionais optassem por instaurar a arbitragem internacional no Brasil ou em país diverso da China. Não haveria restrições com relação à Índia e Rússia, ao menos do ponto de vista normativo.

Ao possibilitar maior clareza ao tratamento jurídico à solução dos contratos internacionais de comércio, caberia aos contratantes calcular as melhores opções. Tal fato conduziria o país por um caminho de desenvolvimento mais dinâmico. De outra forma, as más escolhas contratuais dos contratantes brasileiros, observada a sua autonomia privada na seara internacional, importaria em prejuízos a toda a população.

Considerando que quanto menos tecnologia inserida no país, maiores seriam os custos para adquirir produtos com alto valor agregado proveniente de outros países, vislumbra-se como alternativa a dinamização no setor, sendo um de seus elementos a previsibilidade ante as controvérsias.

\section{REFERÊNCIAS}

ANDRADE, Roberto Campos de. Desenvolvimento sustentável e Direito Internacional. In:Júnior, Alberto do Amaral (Org). Direito Internacional e Desenvolvimento. São Paulo: Manole, 2005. 
AMARAL, Antonio Carlos Rodrigues do. (Coord). Direito do comércio internacional: aspectos fundamentais. São Paulo: Aduaneiras. 2004.

ARAÚJO, Nádia de; JACQUES, Daniela Corrêa. Contratos internacionais no brasil: posição atual da jurisprudência no Brasil. Revista Trimestral de Direito Civil. V. 34. 267-280. 2008

BAPTISTA, Luiz Olavo. Arbitragem comercial e internacional. São Paulo: Lex Magister, 2011.

. Contratos internacionais. São Paulo: Lex Editora, 2011.

CÁRNIO, Thaís Cíntia. Contratos internacionais: teoria e prática. São Paulo: Atlas, 2009

CORDOVIL, Leonor. Antidumping: interesse público e protecionismo no comércio internacional. São Paulo: Editora Revista dos Tribunais, 2011.

FREIRE, José Nantala Bádue. BRICs - Análise Comparativa da Arbitragem Comercial Internacional Institucional. Dissertação de Mestrado. São Paulo: USP, 2014.

GLÜCK, Ulrike; LICHTENSTEIN, Falk. Arbitration in the people's republic of china. In: CMS Guide to Arbitration. Acessado em: eguides.cmslegal.com/arbitration

JUBRAN, Bruno Mariotto. Brasil e Rússia: política, comércio, ciência e tecnologia entre 1992 e 2010. Dissertação de Mestrado. Porto Alegre: UFRGS, 2012.

MISRA, Chakrapani; KAPOOR, Sanjeev. Arbitration in India. In: CMS Guide to Arbitration, 2012. Acessado em: eguides.cmslegal.com/arbitration

SEN, Amartya. Desenvolvimento como liberdade. São Paulo: Companhia das Letras, 2010.

YURYEV, Sergey; KANTYREV, Konstantin. Arbitration in Russia. In: CMS Guide to Arbitration, 2012. Acessado em: eguides.cmslegal.com/arbitration 